\title{
A New Look at Onset Transfer in Indo-European Reduplication: Dissimilation of Consonant Clusters
} Hyung-Soo $\mathrm{Kim}^{+}$

\author{
Hankuk University of Foreign Studies/Jeonju University
}

\begin{abstract}
A new typology of onset cluster reduplication is proposed in Indo-European languages on three premises: 1) Partial reduplication in Indo-European copies the onset cluster in toto; 2) The canonical form of Grassmann's Law type of dissimilation occurs between two complex segments that are sufficiently similar; 3) Such dissimilation of complex segments typically occurs preferentially to an obstruent plus resonant (TR) cluster and to a sibilant plus obstruent (ST) cluster only as a generalization of the preferential rule. The analysis shows that, of the four logically possible rule combinations in the reduplication of TR- vs. ST-initial roots, only three actually occur in Indo-European languages. The fourth type, in which an ST cluster is reduced but a TR cluster remains, is excluded, as it violates the preferential order of dissimilation of consonant clusters. This paper also explains why Sanskrit and Old Irish reduce the ST-initial clusters differently. If the ST cluster acts as a complex segment, the more sonorant S drops, as in the Sanskrit perfect stem ta-stambh- "prop," but if it acts as a consonant cluster, the less sonorant $\mathrm{T}$ drops, as in the Old Irish preterit stem se-scaind- "spring off." This analysis offers a more coherent typology than Zukoff's (2017), which does not properly explain the acrossthe-board $\mathrm{C}_{2}$-copying, a pattern predicted to occur by his permutation of constraints, yet unattested in Indo-European languages and universally nonexistent.
\end{abstract}

Keywords: reduplication, onset cluster, dissimilation, factorial typology, Sanskrit, Gothic, Greek, Old Irish, Indo-European

\footnotetext{
* This is a revised version of my paper presented in a special session on reduplication at the Fall Conference of Language Research Institute, Hankuk University of Foreign Studies (Nov. 1, 2019). I would like to thank the audience and the co-presenters of the session for participation and feedback, especially: Young-ran An, Sunghoon Hong, Jongho Jun, Weon-don Jeong, Jaemok Song and John Stoneham. I am also grateful to the three anonymous reviewers whose comments and criticism have been most helpful in reshaping the article. Needless to mention, I alone take responsibility for any errors.

† Corresponding author: csjennykim@hanmail.net
} 


\section{Introduction}

The typological diversity and peculiarity are what makes Indo-European (IE) reduplication such an interesting and popular topic for study. One issue that has gripped many of the previous works and still remains unresolved is how roots of the type $C_{1} C_{2} V X$ are copied, or more precisely: what is the principle governing the way IE languages reduplicate the root-initial onset cluster? This problem arises because IE reduplication often repeats only one of the consonants in the onset. If an obstruent plus resonant (TR) occurs as a root-initial cluster, it predominantly copies the obstruent $\mathrm{C}_{1}$, as in Goth. gai-grot 'weep (perf.)', OIr. be-brag- 'bleat (pret.)', and Skt. ja-grabh- 'seize (perf.)'.1) If the root begins with a sibilant plus obstruent (ST) cluster, however, it varies its copying: it sometimes repeats the whole cluster, e.g. Goth. skai-skaip 'divide (perf.)', sometimes only one member of the cluster, either $\mathrm{C}_{1}$ as in OIr. se-skann 'spring off (pret.)' or $\mathrm{C}_{2}$ as in Skt. ta-stamb - 'prop (perf.)'. Generally speaking, the same peculiarities are observed in reduplicated present form $\mathrm{s},{ }^{2)}$ and the previous studies initially focused on explaining this variation and change in reduplication of TR- vs. ST-initial roots across IE languages, especially between Gothic and Sanskrit (Kiparsky 1979; Cairns \& Feinstein 1982; Steriade 1988).

Recently, however, a new data that bears on the issue became available in a study of verbal reduplication in Anatolian by Dempsey (2015), which shows that in Hittite imperfect reduplication both TR and ST clusters remain unreduced in the reduplicant. This new data contradicts the dominant view that TR clusters generally reduce to $C_{1}$ in reduplication, thus not only complicating the problem itself but opening a window of opportunity to work on the problem anew. Zukoff (2017) is just such an attempt, which analyzes reduplication of TR- vs. ST-initial roots cross-linguistically, not just in Gothic and Sanskrit but also in other IE languages including Hittite.3) But his factorial typology, based on Base-Reduplicant Correspondence

1) One exception is Hittite, which duplicates both $C_{1}$ and $C_{2}$ of the TR cluster, as will be introduced below. An initial velar in Sanskrit roots typically appears as a palatal stop in the reduplicant, e.g. Skt. ja-grabh-. Throughout the paper reduplicants are boldfaced. Abbreviations for grammatical categories are: inf. $=$ infinitive, perf. $=$ perfect, pres. $=$ present, pret. $=$ preterit. The language abbreviations are: $\mathrm{AG}=$ Ancient Greek, EArab.= Egyptian Arabic, Eng.= English, Goth. $=$ Gothic, Hitt. $=$ Hittite, Khalk. = Khalkha Mongolian, Lt. $=$ Latin, OFr.= Old French, OIr.= Old Irish, OSp. $=$ Old Spanish, Skt.= Sanskrit.

2) Note, for example, Skt. ti-sthati, Lt. si-stō, AG hi-stēmi 'I stand' where the ST onset in the reduplicated present repeats $C_{2}$ in Sanskrit but $C_{1}$ in Latin and Ancient Greek (with change of initial /s/ to $/ \mathrm{h} /$ in AG; cf. Beekes 2011, p. 253).

3) An important work that also proposes a factorial typology of onset transfer in IE reduplication is Fleischhacker (2005), which however does not include Hittite data. Her analysis of onset transfer in 
Theory (BRCT) of McCarthy \& Prince (1995), leaves much to be desired from the language universals and typology point of view because it leaves a gap unexplained. Zukoff (2017, p. 25) derives six patterns of onset cluster reduplication from permutation of constraints, of which five are attested in IE and one unattested; he claims the unattested type to be non-existent universally, even though he cannot find the reason why this gap should exist as a possible yet unattested pattern.

In this paper I would like to reconsider this old problem, based on the insights gained from my earlier study of the phonological process of dissimilation (Kim 1991). In section 2, I review the syllable structure analyses of Kiparsky (1979), Cairns \& Feinstein (1982) and Steriade (1988), as well as the recent BRCT analysis of Zukoff (2017). An alternative analysis is offered in section 3, under the premise that IE partial reduplication copies both $\mathrm{C}_{1}$ and $\mathrm{C}_{2}$ but the complex onset is reduced by dissimilation of consonant clusters. This new cross-linguistic analysis is then compared with the previous analyses, especially with Zukoff's factorial typology. The paper closes in section 4 with a brief summary of this new analysis and its ramifications.

\section{Previous Analyses}

Let us begin then with a synopsis of the data for TR- vs. ST-initial roots reduplicated in major IE languages:

(1) Reduplication of TR- vs. ST-initial roots in IE languages

a. Gothic (Wright 1954, p. 147):

$\begin{array}{llll}\text { TRVX > TV-TRVX: } & \underline{\text { Infinitive }} & \text { Perfect } \\ \text { STVX > STV-STVX: } & \text { gretan } & \text { gai-grot 'weep' } \\ \text { skaidan } & \text { skai-skaip 'divide' }\end{array}$

\footnotetext{
reduplication and loan adaptation is based on the perceptual similarity of onset clusters, under the principle that "phonological processes occur more freely when the results of the process sounds quite similar to the original form" (p. 5). But her analysis seems to raise a teleological problem: that processes are intelligent enough to see the result of their action in advance and act accordingly. Another problem is that part of her argument comes from analysis of alliteration and pun, which I consider, along with loan adaptation, to be distinct from formal linguistic processes such as reduplication. I leave any further critique of her work for the future research.
} 
b. Sanskrit (Whitney 1889; Steriade 1988):

$\begin{array}{llll} & \underline{\text { Root }} & \text { Perfect stem } \\ \text { TRVX > TV-TRVX: } & \text { grabh } & \text { ja-grabh- 'seize' } \\ \text { STVX > TV-STVX: } & \text { stambh } & \text { ta-stambh- 'prop' } \\ \text { Old Irish (Thurneysen 1946) } & \end{array}$

$\begin{array}{llll}\text { TRVX > TV-TRVX: } & \underline{\text { Present }} & \text { Preterit stem } \\ \text { STVX > SV-STVX: } & \text { sceindid } & \text { se-brag- 'fart, bleat' } \\ \text { se-scaind- 'spring off' }\end{array}$

d. Ancient Greek (Smyth 1966; Steriade 1988; Zukoff 2017, p. 29)

$\begin{array}{lll}\text { TRVX > TV-TRVX: } & \underline{\text { Root }} & \underline{\text { Perfect stem }} \\ \text { STVX > e-STVX: } & \text { graph } & \text { ge-graph- 'write' } \\ \text { stel } & \text { e-stalk- 'prepare' }\end{array}$

e. Hittite (Dempsey 2015; Yates \& Zukoff 2018, pp. 211-213)

Root Reduplicated stem

TRVX > TRV-TRVX: par(a)i- pri-p:r(a)i-[pri-p:r(a)i-] 'blow'

STVX > STV-STVX: ištu(/stu/) išdušdu-[istu-stu-] 'become evident'

Some comments on the data and the rule configurations are in order:

1) Conspicuously missing in the above data is Latin, in which there are no TR-initial stems reduplicated. ST-initial stems, on the other hand, vary their reduplication, between STVX > SV-STVX in the present tense but STVX > STV-TVX in the perfect (cf. Niedermann 1953):

$\begin{array}{lll}\text { Present } & \text { Perfect } & \\ \text { stō, si-stō } & \text { ste-tī } & \text { (inf. stāre 'stand', sistere 'set up, stop') } \\ \text { spondeō } & \text { spo-pondī } & \text { (inf. spondere 'betroth') } \\ \text { scindō } & \text { sci-cidī } & \text { (inf. scindere 'cut') }\end{array}$

Obviously this reduplication of the ST-onsets in Latin is a problem even more challenging than the cross-linguistic reduplication of the same cluster in (1), for it varies its copying pattern between two grammatical categories of one same language, Latin. Zukoff (2017, p. 278) considers it to be a case of CV- infixation: Lt. s-te-tī. It is not clear, however, why the reduplication should vary its type of copying between the tenses of present and perfect. Besides, as Buck (1933, p. 292; see also Weiss 2009 , p. 410) notes, the perfect reduplication in IE usually occurs with a fixed /e/, e.g. Lt. ce-cīdī (cf. Lt. caedō 'fall'), Lt. pe-pulī (cf. Lt. pellōo 'hit'), except when the root vowel is $/ \mathrm{i} /, / \mathrm{u} /$ or $/ \mathrm{o} /$, in which case the reduplicant vowel is the same

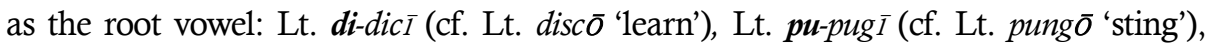


Lt. spo-pondi (cf. Lt. spondeo 'betroth'). This strongly suggests that the reduplication in Lt. stetī (cf. inf. stāre 'stand') is prefixal rather than infixal: Lt. steti < * st-e-stī. Buck (1933, p. 256) suggests 'dissimilation from st-st' as a possible cause for loss of the second /s/, but this analysis also raises a similar question: why would the dissimilation of sibilant plus stop clusters, which drops the stop in the first cluster in the present, changes its direction in the perfect to drop the sibilant in the second cluster? Since the current knowledge I have of Latin reduplication is not sufficient to answer this question, I leave it for future research.

2) Reduplication of ST-initial roots in Ancient Greek (1d) is peculiar in that neither $C_{1}$ nor $C_{2}$ is repeated. What marks the reduplication instead, if it is reduplication at all, is the fixed /e/ attached to the stem: STVX > e-STVX, e.g. AG e-stalka 'prepare (perf.)'. This contrasts with reduplication of TR-initial roots in which the obstruent $C_{1}$ is repeated: TRVX > TV-TRVX, e.g. AG ge-graph 'write (perf.)'. Even though Zukoff (2017, p. 32) includes it in his factorial typology, I consider it inappropriate to analyze the AG configuration in (1d) as a type of cluster-initial roots reduplicated in IE languages. This is because, as both Buck (1933, p. 256$)$ and Sihler $(2008$, p. 490$)$ note, the prefix $e$ - in AG estalka is likely to have developed by chance from regular $C_{1}$ copoying with fixed /e/, i.e. STVX > Se-STVX, the initial /s/ of which then changed to $/ \mathrm{h} /$, as in Gk. hepta (cf. Lt. septem 'seven', cf. Buck 1933, p. 132). Sihler (2008: p. 490) notes expressly that this $e$ - prefix "began with perfects beginning with $\sigma$-plus consonant in which the initial ${ }^{*} \mathrm{~s}$ - of the (reduced) reduplication became $\mathrm{h}$-, and the resulting $\dot{\varepsilon}$ - fell together with the usual form of the augment $\dot{\varepsilon}$-. From such [forms] the $\dot{\varepsilon}$ - spread to words beginning with other combinations." 4$)$ In this sense then, Ancient Greek in its previous stage (i.e. pre-AG) was just like Old Irish in having reduced the onsets of both TR- and ST-initial roots in the reduplicant, until $\dot{\varepsilon}$ 'fell together' with $\dot{\varepsilon}$. The present form AG histemi < *sti-stemi 'stand' (cf. Lt. si-stô), in which the initial /s/ is reduplicated with fixed /i/, indirectly supports this conjecture: the merger occurred with the perfect rather than the present because even though the initial /s/ also changed to $/ \mathrm{h} /$ in the present, the fixed vowel (/i/) is not the same as the vowel of the augment, which is /e/. I therefore consider pre-AG to be of the same type as Old Irish, except for the irregularity caused by this chance development, and will not include Ancient Greek in my typological analysis of TR- vs. ST-initial

4) Note that the diacritic marks ' and ', respectively known as spiritus asper (rough breathing) and spiritus lenis (smooth breathing), are used in Ancient Greek to indicate whether aspiration is present or absent in an initial vowel. Thus $\dot{\varepsilon}-$ is phonetically [he] but $\dot{\varepsilon}-$, [e]. 
roots reduplicated in IE languages.

3) The prothetic vowel /i/ that appears in Hitt. išdušduške- [istu-stu-] is inserted phonologically after reduplication; it is thus not included in the canonical rule STVX > STV-STVX. According to Yates and Jukoff (2018, p. 212), the Hittite example pri-p:r(a)i- [pri-p:r(a)i-] 'blow' is potentially ambiguous between partial reduplication and intensive total reduplication due to the inability of Hittite cuneiform to represent word-initial consonant clusters. But following Dempsey (2015) and Kloekhorst (2008) they assume it to be a case of partial reduplication.

A common question raised in all of the previous analyses has been why TR- and ST-initial roots differ in their onset reduplication cross-linguistically, between Gothic and Sanskrit, for example. As an answer to this question, Kiparsky (1979), Cairens \& Feinstein (1982), and Steriade (1988) offer an analysis based on syllable structure, while Zukoff (2019) gives an analysis of factorial typology under BRCT of McCarthy \& Prince (1995), using well-known constraints such as ANCHOR-L-BR, CONTIG-BR, ${ }^{*} \mathrm{CC}$, and a newly proposed No Poorly-Cued Repetitions constraint ( $\left.{ }^{*} \mathrm{PCR}\right)$. I consider the syllable structure analysis first, then the BRCT analysis.

\subsection{Kiparsky (1979), Cairens \& Feinstein (1982) and Steriade (1988)}

Kiparsky's (1979) explanation relies on the different metrical structure of TR- vs. ST-initial onsets such as (2) below, in which weak (W) and strong (S) labels are assigned according to the well-known sonority hierarchy:5)

(2) Metrical structure of onsets in Gothic and Sanskrit (cf. Kiparsky 1979; Cairns \& Feinstein 1982, p. 210)
a. TR-onset
b. ST-onset
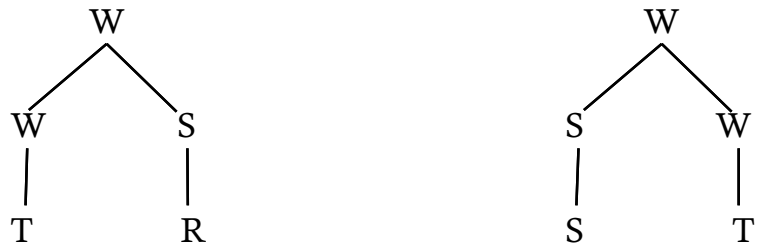

These structures hold for both Gothic and Sanskrit, but the two languages differ in reduplicating ST-initials: the general rule is to reduplicate the first $\mathrm{W}$ of the

5) See below for more on the sonority hierarchy, which plays an important role in the alternative analysis to be presented in section 3 . 
syllable tree (TRVX > TV-TRVX), but if the first segment is an S as in (2b), Gothic reduplicates the nearest nonterminal W above it (STVX > STV-STVX), but Sanskrit, the nearest terminal $\mathrm{W}$ to its right (STVX > TV-STVX).

In Cairns \& Feinstein's (1982, p. 211) analysis, on the other hand, TR- and ST-clusters have onset structures such as (3):6)

(3) Gothic and Sanskrit onset structures
a. TR-onset
b. ST-onset
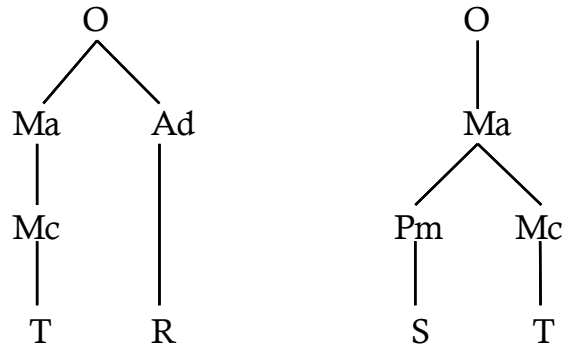

Again these structures hold for both Gothic and Sanskrit but the copying rules differ: For Gothic you copy Ma, which is st in e.g. staut- (cf. Goth. stai-staut 'smitten') but $g$ in grot- (Goth. gai-grot 'wept'), but for Sanskrit, Mc, which is $t$ in e.g. stambh(cf. Skt. ta-stambha) but $s$ in smara- (cf. Skt. sa-smara 'remembered'). Here the rules are simple but the structures are complex, with many additional labels distinguishing segment's role in the hierarchy of the syllable structure.7)

The problem with these explanations is that the rules merely restate the facts structurally without explaining why ST and TR clusters should differ in their behavior of reduplication. For example, Kiparsky's analysis does not explain why the rule repeating the first $\mathrm{W}$ with TR-initial roots changes its target with ST-initial roots, to the nonterminal $\mathrm{W}$ above it in Gothic but to the terminal $\mathrm{W}$ to its right in Sanskrit. He mentions that clusters such as $s p$-, st- and $s k$ - alliterate as units in Germanic versification, which suggests that they act as a more closely bound unit in Gothic, but this insight is not reflected in his metrical structure of the onset; nor is it explicit in the rule that refers to 'nonterminal $\mathrm{W}$ above the first $\mathrm{W}$ ' in the syllable tree. ${ }^{8)}$ Similarly, Cairens \& Feinstein's analysis fails to explain why Gothic should

6) $\mathrm{Cf} . \mathrm{Ma}=$ Margin, $\mathrm{Ad}=$ Adjunct, $\mathrm{Mc}=$ Margin core, $\mathrm{Pm}=$ Pre-margin.

7) Cairns \& Feinstein base their distinction of the onset structure between TR- and ST- on Greenberg's (1978) implicational universals on initial consonant sequences.

8) Another question one should consider is whether the repetition of onset by alliteration and 
copy the whole margin (Ma) of the onset but Sanskrit only the margin core (Mc).

Steriade (1988) also bases her explanation of onset reduplication in Gothic and Sanskrit on syllable structure but makes use of the extrasyllabicity of /s/ in ST clusters. To explain the different behaviors of TR- vs. ST-initial roots in Gothic, for example, she assumes the following structures for Gothic stems stau- and grot-:

(4) Structures for ST- and TR-onsets in Gothic
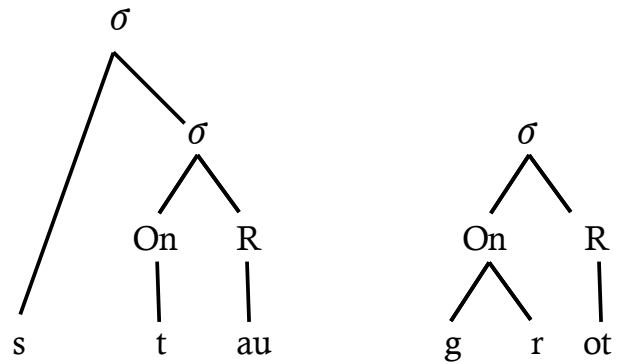

Following Kiparsky (1981), she first defines the extrasyllabic /s/ joined directly to the syllable node in Goth stau- as an adjunct, and then proposes that " $\cdots$ the prefix syllable of Gothic $\cdots$ is restricted to having a simple onset but does not bar the presence of adjuncts. The difference between Sanskrit and Gothic $\cdots$ could be attributed to the fact that Sanskrit reduplication applies before adjuncts are formed"(p. 139). This analysis is similar to the preceding ones in that it seeks explanation by positing different structures of onset, except that it recognizes the 'extrasyllabicity' of initial /s/, which, though excluded by the general rule of copying initial onset consonant of the base syllable, appears on the surface because adjuncts are allowed in the reduplicative prefix. In Sanskrit, on the other hand, the 'unlicenced' extrasyllabic initial /s/ is removed before such adjunction of a stray element occurs.

reduplication should be considered under the same purview. This is because the former is essentially a 'play on word' for rhythmic purposes and typically targets the first segment, while the latter is in origin a repetition of words in part or whole for 'semantic emphasis' and, as will be argued below, in principle copies the onset cluster in toto. I thus leave the matter of finding any possible connection between Germanic alliteration and reduplication for future research. Also left for the future are echo reduplication in Khalkha loan words in which ST initials are replaced obligatorily by $/ \mathrm{m} /$, e.g. Khlk. standard mandard 'standard and the like', but TR initials only optionally, e.g. Khlk. klinik minik/mlinik 'clinic and the like' (Song 2018, p. 156) as well as examples of vowel insertion in loanword adaptations of TR and ST initials, which are often repaired differently, by anaptyxis in the former but by prothesis in the latter, e.g. EArab. [bilastik] 'plastic' but [?iski] 'ski (with / $/$ / epenthesis)' (Fleischhacker 2005, p 40; Broselow 2015). I thank Profs. Jaemog Song and Jongho Jun for raising these issues. 
Steriade also proposes an alternative explanation that can avoid the 'structural complexity entailed by the difference between adjunct and onset'. This second explanation is similar to the first one in making use of the extrasyllabicity but differs in letting the prosodic categories do the work: she allows some extrasyllabic element to be included in the prefix and contends that (unlike in Sanskrit) "the reduplicating affix in Gothic is not a plain syllable but a minimal word containing a CV syllable"(p. 139). Gothic copies ST in toto because it reduplicates a minimal word in which a CV syllable is allowed to co-occur with the extrasyllabic /s/, while Sanskrit reduplicates a plain CV prefix. This explanation raises the same type of question: Why does reduplication occur on word level in Gothic but on stem level in Sanskrit?

The position of this paper is that the copying variation is not caused by syllable structure difference but by different propensity for TR- vs. ST-onsets to reduce by dissimilation of consonant clusters, the canonical form of which occurs between two complex segments. I argue that the consonants in TR are more likely to be bound as one unit to become a complex segment than those in ST because the sonority difference between the two consonants is greater in the former than in the latter. For this reason TR is reduced by dissimilation of consonant clusters more readily than ST when reduplicated. The details of this alternative approach are presented in section 3 .

\subsection{BRCT analysis of Zukoff (2017)}

Having seen the problems of the analyses that rely on syllable structure of TRvs. ST-initial roots, I now turn to a more recent constraint-based analysis of Zukoff (2017), who proposes a factorial typology of TR- vs. ST-initial roots reduplicated in all five IE languages in (1). His typology is built on two considerations: 1) a distinction between across-the-board copying and cluster-dependent copying; 2) a new constraint, No Poorly-Cued Repetitions ( $\left.{ }^{*} \mathrm{PCR}\right)$, that interacts with well-established constraints such as ${ }^{*} \mathrm{CC}$ (no sequence of two consonants), Contiguity-BR (no skipping by reduplication), Anchor-L-BR (the segment at the left edge of the reduplicant must correspond with the segment at the left edge of the base) and Onset (syllables must have onset).

The *PCR, which is based on perceptual cues, is a constraint that penalizes repetition of two identical consonants across a vowel if this transvocalic repetition occurs before an obstruent. Thus (cf. Zukoff 2017, p. 27): 
(5) No Poorly-Cued Repetitions ( $\left.{ }^{*} \mathrm{PCR}\right):{ }^{*} \mathrm{C}_{\alpha} \mathrm{VC}_{\alpha} / \mathrm{C}_{\text {-sonorant] }}$

For each sequence of repeated identical consonants separated by a vowel $\left(\mathrm{C}_{\alpha}\right.$ $\mathrm{VC}_{\alpha}$ ), assign a violation * if that sequence immediately precedes an obstruent.

Zukoff's account culminates in a factorial typology of constraints, complete with the constraint ranking for each type. (6) is a simplified version of it; the data that had been presented in (1) and some minor details that do not directly concern the current discussion have been omitted.

(6) Factorial typology of constraints (cf. Zukoff 2017, p. 32)

1. Across-the-board copying patterns

a. Across-the-board cluster-copying:

TRVX $>$ TRV-TRVX and STVX $>$ STV-STVX

Language: Hittite

Ranking: Anchor-L-BR, Contig-BR, (Onset) $>>{ }^{*} \mathrm{CC},{ }^{*} \mathrm{C}_{\alpha} \mathrm{VC}_{\alpha} / \mathrm{C}_{\text {--sonorant] }}$

b. Across-the-board $\mathrm{C}_{1}$-copying:

TRVX $>$ TV-TRVX and STVX $>$ SV-STVX

Language: Old Irish

Ranking: Anchor-L-BR, Onset, ${ }^{*} \mathrm{CC}>>{ }^{*} \mathrm{C}_{\alpha} \mathrm{VC}_{\alpha} / \mathrm{C}_{[- \text {-sonorant] }}$, Contig-BR

c. Across-the-board $\mathrm{C}_{2}$-copying:

TRVX $>$ RV-TRVX and STVX $>$ TV-STVX

Language: Unattested

Ranking: Contig-BR, (Onset), ${ }^{*} \mathrm{CC}>>$ Anchor-L-BR, ${ }^{*} \mathrm{C}_{\alpha} \mathrm{VC}_{\alpha} / \mathrm{C}_{\text {-sonorant] }}$

2. Cluster-dependent copying patterns

d. TRVX-C ${ }_{1}$-copying but STVX-cluster-copying:

TRVX > TV-TRVX but STVX > STV-STVX

Language: Gothic

Constraint ranking: ${ }^{*} \mathrm{C}_{\alpha} \mathrm{VC}_{\alpha} / \mathrm{C}_{\text {[-sonorant] }}$, Anchor-L-BR, Onset $>$ Contig-BR

e. TRVX- $\mathrm{C}_{1}$-copying but STVX-C $\mathrm{C}_{2}$-copying:

TRVX> TV-TRVX but STVX > TV-STVX

Language: Sanskrit

Constraint ranking: ${ }^{*} \mathrm{C}_{\alpha} \mathrm{VC}_{\alpha} / \mathrm{C}_{\text {[-sonorant] }}$, Onset, ${ }^{*} \mathrm{CC}>>$ Anchor-L-BR $>>$ Contig-BR

f. TRVX-C ${ }_{1}$-Copying but STVX-non-copying:

TRVX > TV-TRVX but STVX > e-STVX 
Language: Ancient Greek

Constraint ranking: ${ }^{*} \mathrm{C}_{\alpha} \mathrm{VC}_{\alpha} / \mathrm{C}_{\text {[-sonorant] }}$, Anchor-L-BR, ${ }^{*} \mathrm{CC}>>$ Onset, (Contig-BR)

Three possible types are given under the across-the-board copying (6.1), which simply copies either $\mathrm{C}_{1}$ or $\mathrm{C}_{2}$, or both, regardless of whether the onset of the base is TR or ST. Since what is being considered here is reduplication of TR- vs. ST-initial roots, these three types exhaust the logical possibility in across-the-board copying. However, only two types actually occur: across-the-board cluster-copying $\left(\mathrm{C}_{1} \mathrm{C}_{2} \mathrm{~V}\right.$ $\left.\mathrm{C}_{1} \mathrm{C}_{2} \mathrm{VX}\right)$ in Hittite and across-the-board $\mathrm{C}_{1}$-copying $\left(\mathrm{C}_{1} \mathrm{~V}-\mathrm{C}_{1} \mathrm{C}_{2} \mathrm{VX}\right)$ in Old Irish. The third type, across-the-board $\mathrm{C}_{2}$-copying $\left(\mathrm{C}_{2} \mathrm{~V}-\mathrm{C}_{1} \mathrm{C}_{2} \mathrm{VX}\right)$, is unattested, not only in Indo-European but also in languages outside of the IE family. Zukoff (2017, p. 25) says that this gap is possibly "an accidental one and not a significant one" and that "there is no glaring reason why such a pattern should be unattested". I return below to this gap in the typology to show that his idea of across-the-board copying is mistaken because it does not take into consideration the characteristic difference in the onset structure between TR and ST, the fact that $C_{2}$ is more sonorant than $C_{1}$ in TR but vice versa in ST. I will argue that the gap is not accidental because there is a 'significant' reason why no across-the-board $\mathrm{C}_{2}$-copying is possible: when a fully copied onset cluster reduces by dissimilation of consonant clusters, it is usually the more sonorant consonant that drops, which is $C_{2}$ in TR (thus $C_{1}$-copying) but $C_{1}$ in ST (thus $\mathrm{C}_{2}$-copying).

The cases of Hittite cluster-copying and Old Irish $\mathrm{C}_{1}$-copying are similarly explained. Hittite is simply a case in which no dissimilation of consonant clusters has occurred. It thus represents the state that has arisen in all five languages immediately after reduplication. In Old Irish, the ST cluster has an onset structure different from Sanskrit: while the ST onset forms a complex segment in Sanskrit, in Old Irish it forms a cluster in which two consonants are concatenated with no tight bonding between them; as such the dissimilation of consonant clusters drops the more sonorant $\mathrm{S}$ in the former but the less sonorant, thus weaker, $\mathrm{T}$ in the latter.

For cluster-dependent copying patterns (6.2), Zukoff makes use of the distinction between TR- vs. ST-initial roots: while TR-initial roots uniformly show $\mathrm{C}_{1}$-copying, ST-initial roots vary their copying between $\mathrm{C}_{1} \mathrm{C}_{2}$ cluster-copying (Gothic), $\mathrm{C}_{2}$-copying (Sanskrit) and non-copying (Ancient Greek). Missing in this list is the $\mathrm{C}_{1}$-copying of ST cluster in Old Irish, which with the same $C_{1}$-copying of TR cluster exhibits across-the-board $\mathrm{C}_{1}$-copying. This shows that his typological calculation has not 
considered all logically possible types: since like Gothic and Sanskrit Old Irish has $\mathrm{C}_{1}$-copying for TR cluster, the analysis should have included the $\mathrm{C}_{1}$-copying of ST cluster in Old Irish as a legitimate type of cluster-dependent copying, and compared it to other types of ST-copying in Gothic and Sanskrit.

There is, on the other hand, no compelling reason to include the non-copying case in Ancient Greek, because it is doubtful that such a case is a possible type in reduplication of ST-initial bases in languages of the world. As mentioned in discussing the data in (1), the fixed $e$ - prefix for AG perf. $\boldsymbol{e}$-stalka is an accidental development related to the history of Greek alphabet.9) It began as $\dot{\varepsilon}[$ [he], a regular development from $\mathrm{C}_{1}$-copying of ST-cluster (STVX > Se-STVX) with subsequent

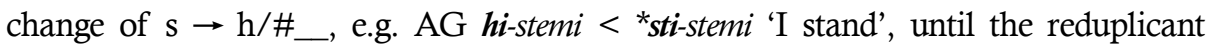
$\dot{\varepsilon}$-[he] fell together with the augment $\dot{\varepsilon}$-[e], leaving only the fixed vowel to mark the perfect form. As Zukoff (2017, p. 308) assumes, Ancient Greek of earlier times, i.e. pre-AG, actually belongs to the same type as Old Irish, in that it has the across-the-board $\mathrm{C}_{1}$-copying. ${ }^{10)}$

To sum up the discussion so far: three types of copying occur in reduplication of ST-initial roots: 1) ST remains unreduced (Gothic, Hittite); 2) S drops (Sanskrit); 3) $\mathrm{T}$ drops (Old Irish and possibly pre-Ancient Greek). In contrast, only two types occur in reduplication of TR-initial roots: 1) TR remains unreduced (Hittite); 2) R drops (Gothic, Sanskrit, Old Irish, and Ancient Greek). Now, the question to be asked is why ST and TR should differ in their number of variations in onset clusters reduplicated in IE languages. I turn to the alternative analysis section to properly answer this question.

\section{Alternative Analysis: Dissimilation of Consonant Clusters}

The search for an alternative analysis begins with the following questions on the reduplication rules in (6). Some of these questions have been raised previously but not properly answered, while others are new questions that can help us better understand the complexities involved in resolving the problem.

9) See Gnanadesikan (2009, chap. 12) for a brief history of Greek alphabet.

10) Zukoff $\left(2017\right.$, p. 308) claims that Proto-IE root-initial clusters had across-the-board $C_{1}$-copying, against the traditional view that advocates $\mathrm{C}_{1}$-copying for TR onset but cluster copying for ST onset. These two views contrast with the view of this paper that both TR and ST copy onset clusters in toto. For further details, vide infra. 
(7) Questions on rule configurations of IE reduplication

1) Why does reduplication reduce TR clusters in preference to ST clusters, as in Gothic for example?

2) When both TR and ST clusters reduce, why does reduplication in Sanskrit drop $\mathrm{R}$ in the former but $\mathrm{S}$ in the latter, although such reduction goes against the simple, across-the-board rule that elides either $C_{1}$ or $C_{2}$ ?

3) Why is it the case that TR always drops R but ST varies its elision, dropping $\mathrm{S}$ in Sanskrit but $\mathrm{T}$ in Old Irish?

4) Why is it the case that when ST reduces (to either S or T), TR always does the same, e.g. Old Irish and Sanskrit, but when TR reduces (to T), ST sometimes does not do the same, e.g. Gothic? And it seems to be the case that if TR remains unreduced, ST also does, e.g. Hittite, but if ST remains, TR does not follow suit, cf. question 1) above.

The first thing one should refrain from to answer these questions is to think that the default reduplication in IE copies only one consonant of a $C_{1} C_{2}$ onset, either $\mathrm{C}_{1}$ or $\mathrm{C}_{2}$, which seems to have been the premise of every previous analysis. One runs into difficulties due to this idea because now one is obliged to explain the cases such as Gothic, for which it is said that the ST-cluster acts as one unit but the TR-cluster does not. The new analysis assumes that reduplication copies the onset clusters in toto, but dissimilation of consonant clusters reduces them to one consonant. This alternative analysis is based on careful investigation of the dissimilation process and its conditions in world's languages, which show a common thread, namely that dissimilation often occurs between complex segments, as in Grassmann's Law in Greek and Sanskrit: AG ti-themi < thi-themi and Skt. da-dhami $<$ *dha-dhami 'I do'.

Also important is the notion that rules typically occur preferentially. Thus, even though the root-initial TR and ST form a natural class of biconsonantal onset (CC) and both are reduplicated in IE languages, with the sonority difference between $C_{1}$ and $\mathrm{C}_{2}$ greater in the former than in the latter, TR is more likely to form a complex segment, thus more likely to reduce by dissimilation of consonant clusters than ST. An ST cluster may reduce by dissimilation in a language, but only when TR has already done so. This principle of preferential rule application and its generalization is a cornerstone of Foley's phonological theory (Foley 1977), and is the reason why reduplication of TR- and ST-initial roots in IE behave differently, as in Gothic for example. 
Finally, it is sometimes instructive to distinguish between questions regarding a rule's application and those that concern its reflex. Whether a phonological rule occurs or not in a language is typically determined by the preferential conditions on that rule, and often finding such conditions is all an analyst has to do to successfully answer questions that arise in a phonological phenomenon. But sometimes one finds that an analysis based on application or non-application of a phonological rule does not come to a full explanation. In such cases, it often helps to look at the phenomenon from a different perspective, as a reflexology problem. This is because sometimes the application of a phonological rule may be defined by one condition but its reflexes by another.

This is indeed what happens in IE onset cluster reduplication, in which the reduction or retention of TR- vs. ST-initials is governed by the condition of sonority difference between $C_{1}$ and $C_{2}$, but the same rule, which consistently drops the more sonorant $\mathrm{R}$ in TR clusters, drops sometimes the more sonorant $\mathrm{S}$ (in Sanskrit) but sometimes the less sonorant $\mathrm{T}$ (in Old Irish) in ST clusters. Even though both Sanskrit and Old Irish reduce ST clusters, the reduction cannot be explained by looking at the rule's condition only, because the two languages differ in reducing ST clusters. Rather, it is best to consider the problems separately, as I have done at the beginning of this section: of the four questions in (7) the first and the last ones concern the condition on preferential reduction of TR- vs. ST-onsets and its generalization, while the middle ones probe the reasons for the different reflexes of the ST- cluster reduced under the same condition.

With these guidelines in mind, I finally present the alternative analysis in the following subsections, beginning with conditions on dissimilation of consonant clusters (3.1), followed by explanation of why Sanskrit and Old Irish reduce the ST- onsets differently in reduplication (3.2).

\subsection{Conditions on dissimilation of consonant clusters}

As mentioned earlier, a premise of the alternative analysis is that the IE partial reduplication copies the onset cluster in toto, but dissimilation of consonant clusters systematically reduces them under preferential conditions, yielding various onset shapes in the reduplicant. A first step in this scheme of explanation is thus to gather the relevant data to find out what kind of clusters dissimilate in languages. Although examples of such dissimilation are not legion, they are quite common across languages, as the following examples demonstrate: 
(8) Dissimilation of consonant clusters

a. CGVCG > CVCG (Foley 1985; Kim 1991, pp. 97-100)

C': AG ti-themi <*thi-themi, Skt. da-dhami 'I do' (cf. Grassmann's Law)

$\mathrm{C}^{\mathrm{w}}$ : Lt. quinque Sp. cinco 'five' (cf. Lt. quintus Sp. quinto [kinto] 'fifth')

C': AG ke-ktemai < *k'e-k'emai 'acquire' (cf. AG ktaomai < *k'aomai, Skt. ksayati)

b. CLVCL > CVCL (Foley 1974; Kim 1991)

Latin

prosternare

triple

flebilis

tremulare

\section{Spanish}

postrar 'prostrate'

tiple 'treble'

feble 'feeble'

temblar 'tremble'

c. NCVNC > NCVC: Kuanyama Rule of dissimilation (Meinhof 1932; Kim 1999)11)

Kuanyama
ongadu <*ongandu
ongobe <*ongombe
ombabi <*ombambi

Herero
ongandu 'crocodile'
ongombe 'beast'
ombambi 'steenbuck'

The most well-known of these examples is the Grassmann's Law in (8a); as an example of dissimilation par excellence, it is also the most worked on. Traditionally, Grassmann's Law has been described as a case of dissimilation in which an aspirated consonant deaspirates when another aspirate follows in the same word. But in view of the examples of similar dissimilation in (8a), it can be analyzed as a case in which two similar, or rather identical, clusters of consonant plus glide (CG) clusters dissimilate. This interpretation also makes sense in view of the examples in (8b) and (8c), which show the same type of dissimilation, between clusters of consonant plus liquid (CL) and clusters of nasal plus stop (NT).

I have referred to Grassmann's Law and other examples in (8) as dissimilation of 'consonant clusters', but it would be more correct to call them dissimilation of 'complex segments', as the two concatenated consonants that participate in the rule typically have a compound structure, with one of $\mathrm{C}_{1} \mathrm{C}_{2}$ acting as the primary articulation and the other as the secondary. This then is the canonical form of

11) Note that the nasal in the second nasal compound drops because here the second (rather than the usual first) of two similar consonant clusters weakens by dissimilation, which is interpreted as a strength fluxion in Foley (1981). For further explanation of this reversal in direction of dissimilation, see $\operatorname{Kim}(1991,1999,2019)$. 
Grassmann's Law type of dissimilation. The reason I call it dissimilation of consonant clusters rather than dissimilation of complex segments or compounds is because, as will be discussed below, this canonical rule sometimes generalizes to include cases in which the two consonants that participate in the rule are merely concatenated as in a true consonant cluster. Thus it would be best to understand that when I refer to dissimilation of consonant clusters, it refers to dissimilation between two complex segments as well as two concatenated consonants, with the former as the canonical rule and the latter as its generalized type.

Theoretically, the two clusters, one in which the two consonants are in compound relationship and called a complex segment, and the other in which the two are in mere concatenation, are distinguished by how their constituents are bound to each other. In Foley's phonological theory (Foley 1977, pp. 39-43), they are distinguished on the gamma parameter, also known as the bond strength scale, on which complex segments typically have $\gamma 2$, but the concatenated clusters, $\gamma 1$, which means that the two elements are bound more tightly in the former than in the latter.

(9) Examples of Foley's gamma phonological scale (cf. Foley 1977, p. 43)

$\begin{array}{lll}\text { r1 } & \gamma^{2} & \text { r3 } \\ \mathrm{kw} & \mathrm{k}^{\mathrm{w}} & \mathrm{p} \\ \mathrm{ai} & \mathrm{a}^{\mathrm{y}} & \mathrm{e} \\ \mathrm{au} & \mathrm{a}^{\mathrm{w}} & \mathrm{o} \\ \mathrm{th} & \mathrm{t}^{\mathrm{h}} & \theta \\ \mathrm{Nd} & \mathrm{N}_{\mathrm{d}} & \mathrm{n}\end{array}$

In plain terms, the two elements with $\gamma 1$ strength are merely concatenated as a cluster, and those with $\gamma 2$ strength are diphthongal (diphthongal in the sense that two sounds come together as one unit, cf. AG di- 'two' and AG phthongos 'sound'), while those with $\gamma 3$ strength are monopthongal, whose relationship with the corresponding $\gamma 2$ diphthongs or $\gamma 1$ clusters is revealed by contraction rules such as $\mathrm{k}^{\mathrm{w}} \rightarrow$ p, e.g. AG hepomai (cf. Lt. sequor 'follow') and ai $\rightarrow$ e, e.g. Skt. mahendra < *maha-indra 'great Indra' (Foley 1977, p. 39).

Note in the above list that the aspirate $\left(/ \mathrm{t}^{\mathrm{h}} /\right)$ and the nasal compound $\left({ }^{\mathrm{N}} \mathrm{d}\right)$, both of which participate in the dissimilation of consonant clusters in (8), have $\gamma^{2}$ strength. This confirms our initial suspicion that the canonical form of dissimilation occurs between two complex segments, or segments with $\gamma 2$ strength. In addition, there is evidence that the Spanish rule in (8b), CLVCL $\rightarrow$ CVCL, also occurs 
between two complex segments. This can be detected by considering the well-known stress rule in Latin, which says that: 'Stress the penult if that syllable is heavy; otherwise stress the antepenult'. But in examples such as Lt. cólubra 'snake (fem.)', the stress falls on the antepenult, even though the penult appears to be closed, therefore heavy. The standard explanation is that the stop plus liquid cluster, known as muta-cum-liquida, counts as one consonant, making the penult light because it is open with a short vowel, i.e. Lt. cólu.bra. In the descendent Romance languages, however, it has become a consonant cluster (a change from $\gamma^{2}$ to $\gamma 1$ ), with the syllable boundary falling between the stop and the liquid ( $\left.{ }^{*} c o . l u b . r a\right)$, and the stress thus falling on the heavy penult. A corroborating evidence for this change in syllable structure is found in the Romance reflexes of the same word, e.g. OSp. culuebra and OFr. couluevre where the short /o/ has diphthongized to /ue/ under stress (Scheer \& Segeral 2005). Since the above dissimilation rule occurs as a change from Latin to Spanish, and dissimilation of consonant clusters in its canonical form occurs between two complex segments, it is likely that the muta-cum-liquida clusters that participate in the dissimilation process in (8b) also had a compound structure with $\gamma 2$ strength.

Note now that the complex segments that dissimilate in (8) form a natural class: they are all TR clusters, composed of an obstruent and a resonant, though not necessarily in that order. Note also that this insight, in conjunction with the principle of preferential rule application, answers the question asked in (7.1) regarding the reduplication in Gothic: TR onsets reduce in preference to ST onsets because TR is more likely to form a complex segment than ST, and dissimilation of consonant clusters occurs preferentially to complex segments.

How TR forms a complex segment in preference to ST is defined by the well-known sonority scale, for which a number of versions exist, with some disagreements in its details; but all seem to agree in principle that vowels are more sonorant than consonants, of which the resonants, in the order of glides, liquids, and nasals, are more sonorant than the nonresonants, with their sonority decreasing in the order of fricatives, affricates, and stops. The same principle underlies Foley's rho phonological parameter: 
(10) The sonority scale (Foley 1977; cf. Kiparsky 1979; Clements 1990)

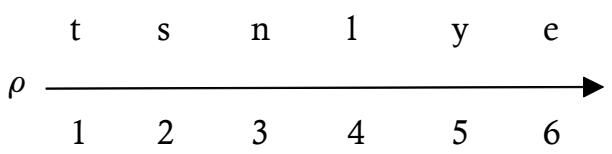

( $t$ for stops, $s$ for sibilants, $n$ for nasals, $l$ for liquids, $y$ for glides and $e$ for vowels)

On this scale, TR clusters that are reduced by dissimilation in (8) have intra-cluster sonority difference between 2 and $4\left(\left|C_{1}-C_{2}\right|=2 \sim 4\right)$. For example, the nasal compound $(\mathrm{NC})$ has the sonority difference $2(|\mathrm{n}-\mathrm{t}|=2)$; the muta-cum-liquida $(\mathrm{CL})$, $3(|t-1|=3)$, and the stop plus glide $(C G), 4(|t-y|=4)$. The ST cluster, composed of a sibilant and an obstruent, has the sonority difference value 1 on the above scale: $|\mathrm{s}-\mathrm{t}|=1$. Therefore, biconsonantal clusters with sonority difference greater than 2 $\left(\left|C_{1}-C_{2}\right| \geq 2\right)$ are more likely to form a complex segment. This proposal is not new. Based on Greenberg's (1978) implicational universals regarding initial consonant clusters, Steriade (1988, p. 137) stipulates that a sequence with the least sonorous segment followed by the most sonorous one is expected to be a complex segment. That all the examples of dissimilation in (8) are TR is not accidental because dissimilation of consonant clusters typically occur between two complex segments. ${ }^{12)}$

In previous analyses, the same attempt to explain Gothic reduplication was made by drawing different structures of the onset cluster in a syllable. But what is missing in all of these attempts is the realization that TR clusters act as one unit, and are more likely to do so than ST clusters, due to the difference in bond strength between them, with $(\mathrm{T}, \mathrm{R})^{2}$ for the former but $(\mathrm{S}, \mathrm{T})^{1}$ for the latter. ${ }^{13)}$ Graphically, the different onsets can be distinguished as in (11).

12) A reviewer disagreed to this statement citing affricates such as [tf] in English, which is a complex segment even though the sonority difference between the stop and the fricative is minimal. I think these phonetic affricates are endogenously complex, with greater bonding $(\gamma 3)$ between the two constituent segments. They are thus monophthongal rather than diphthongal, which is why they are often written with one symbol, e. g. [t $\left.\int\right]=[\check{c}]$.

13) The superscript numbers here indicate the gamma strength. 
(11) Structure of TR vs. ST onsets in Gothic (cf. Sheer and Segeral 2005, p. 235)
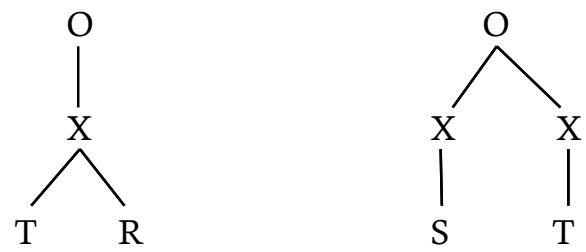

In Sanskrit, on the other hand, not only TR but also ST has the bond strength 2 so that they both undergo dissimilation: $(\mathrm{T}, \mathrm{R})^{2}$ and $(\mathrm{S}, \mathrm{T})^{2}$. This is accomplished by changing the intra-cluster sonority difference condition, from $\left|C_{1}-C_{2}\right| \geq 2$ in Gothic to $\left|\mathrm{C}_{1}-\mathrm{C}_{2}\right| \geq 1$ in Sanskrit, so that not only TR but ST may also form a complex segment and undergo dissimilation of consonant clusters. The structures of TR and ST onsets in Sanskrit can be represented as in (12):

(12) Structure of TR vs. ST onsets in Sanskrit
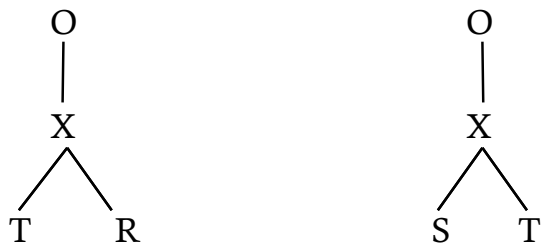

An interesting corollary to this analysis is that a TR cluster such as sm, which has the same sonority difference as ST on the sonority scale in (10), i.e. $(|\mathrm{s}-\mathrm{n}|=1)$, also reduces in Sanskrit, as in Skt. sa-smara < *sma-smara 'remembered', but still follows the principle that it is the more sonorant member of the complex segment that drops by dissimilation. Note that this analysis answers the last question in (7): since TR forms a complex segment more readily than ST, it is more likely to undergo dissimilation of consonant clusters and reduce; an ST cluster may reduce only when a TR cluster has already done the same, so that if TR remains unreduced in a language, ST always does the same.

Since the foregoing discussion implies that TR and ST clusters behave separately in dissimilation of consonant clusters, there are four logically possible rule configurations with regard to reduction of TR- vs. ST-initial roots reduplicated in IE languages: 
(13) Possible reduplication types for TR- vs. ST-initial roots in IE

1) $T R$ and $S T$ both remain unreduced (Hittite)

2) TR reduces but ST remains (Gothic)

3) ST reduces but TR remains (unattested and non-existent)

4) TR and ST both reduce (Old Irish, Sanskrit, and pre-Ancient Greek)

Of these four logically possible types, I claim that 1), 2) and 4) are linguistically possible types, but 3 ) is not a type to be found in any of the world's languages. Of the five Indo-European languages that are being considered here, Hittite belongs to type 1), Gothic to type 2), and Old Irish and Sanskrit to type 4). Ancient Greek must have also belonged to type 4) in its previous stage (i.e. pre-AG) until the reduplicant $\dot{\varepsilon}-[$ he] fell together with the augment $\dot{\varepsilon}$ [e], making its original type no longer visible.

Still remaining to be explained is the different reflexes of ST onset in Old Irish and Sanskrit: Skt. ta-stamb ${ }^{h}$ vs. OIr. se-skann. The latter's reduction of ST is peculiar in that the less sonorant consonant $\mathrm{T}$ drops by dissimilation of consonant clusters, unlike in Sanskrit where the more sonorant $\mathrm{S}$ drops. As mentioned earlier, this reflexology problem is independent of the problem that concerns the rule's application; it thus deserves a separate section for discussion.

\subsection{The transfer of ST-onset reduplicated in Sanskrit and Old Irish}

The foregoing discussion has made it clear that in dissimilation of complex segments, it is the more sonorant, secondary, member of the compound that drops. This has been based on two facts: 1) TR onset always drops the more sonorant $\mathrm{R}$ in all IE languages, except in Hittite where it remains unreduced (Hitt. pri-p:r(a)i-[pri-p:r(a)i-f); 2) ST onset also drops the more sonorant S, albeit only in Sanskrit (Skt. ta-stambh-). I have maintained this principle despite the fact that the less sonorant consonant drops in Old Irish (se-skann-). ${ }^{14)}$ Two questions thus arise regarding this principle: 1) Why does dissimilation drop the more sonorant, secondary member of a complex segment, even though it is tightly bound (with $\gamma 2$ ) to its primary member?; 2) Why does the same principle always drop the more sonorant consonant (R) in TR clusters but fail to do the same in ST clusters?

14) Note that the ST-onsets in Gothic (skai-skaib) and Hittite (išdušdu-[istu-stu-I) are retained because the dissimilation rule itself does not occur in Hittite, while it occurs to a TR cluster in preference to an ST cluster in Gothic. 
The first question, also raised by one reviewer, is interesting but answering it is beyond this paper. The question is related to the more basic question: Why does dissimilation of such complex segments occur? What can be said at this point is that repetition of same segments at a distance motivates it and the reason why the more sonorant consonant deletes by dissimilation is because it functions as a secondary articulation. Whether this secondary coarticulation spills over to the intervening vowel and causes misperception by the listener (Ohala 1981; see also Garret and Johnson 2011) is a matter that can perhaps be properly investigated in the realm of experimental acoustic-auditory phonetics.

A more pressing issue is the second question: Why does ST rather than TR vary its cluster reduction, dropping the more sonorant $\mathrm{S}$ in Sanskrit but the less sonorant $\mathrm{T}$ in Old Irish? Again, the answer to this question is found in the greater propensity for TR to form a complex segment than ST, due to the intra-cluster sonority difference greater in the former than in the latter.

The fact that TR loses the more sonorant $\mathrm{R}$ by dissimilation shows that it functions as a complex segment in both Sanskrit and Old Irish. The same cannot be said of the ST cluster: Had it also functioned as a complex segment in both languages, it would have dropped the more sonorant $\mathrm{S}$, and there would have been no difference in the reflex of ST by dissimilation. This shows that ST in Sanskrit and Old Irish is structurally different: it is a complex segment in Sanskrit with S serving as a secondary consonant but it is a consonant cluster in Old Irish, with both consonants merely concatenated as a cluster. In other words, the two are distinguished by bond strength: the two consonants are bound more tightly in the former $(\gamma 2)$ than in the latter $(\gamma 1)$.

Viewing the ST cluster in Old Irish as a consonant cluster rather than a complex segment has an advantage: now the elision of $\mathrm{T}$ in the ST cluster by dissimilation can be related to cluster simplification, which also drops a consonant, often the least sonorant one, in a group of more than three consonants, e.g. Eng. whistle [wısl].15) Note that $\mathrm{T}$ in ST is also in a consonant cluster, albeit a biconsonantal one. It is thus plausible that in Old Irish (and pre-AG) ST functions as a consonant cluster rather than a complex segment and the less sonorant $\mathrm{T}$ drops as a result of dissimilation because it is often the least sonorant member of a cluster that drops by cluster simplification.

15) This is not the only condition on cluster simplification. Note, for example, the same /t/ does not drop in Eng. gentle and Eng. disgruntle. The position of a consonant in the cluster may also be important: it is often the middle consonant that drops, as in this example. 
On the other hand, as mentioned earlier in section 3.1, the ST cluster in Gothic also has bond strength 1 , because, while TR as a complex segment with bond strength 2 loses the more sonorant $\mathrm{R}$ by dissimilation, ST as a cluster remains unreduced by the same dissimilation. A new question thus arises at this point: Why does the ST cluster reduce by dissimilation in Old Irish but not in Gothic, even though the cluster is said to have bond strength 1 in both languages? Again the answer is found in preferential rule application and its generalization. Since the canonical form of dissimilation typically occurs between two complex segments and since TR with greater intra-cluster sonority difference is more likely to form a complex segment than ST, dissimilation occurs to TR in preference to ST, as in Gothic where ST is not a complex segment but a consonant cluster with bond strength 1 .

This preferential rule then generalizes so that dissimilation may occur to ST as well as TR. This can happen in two ways. First, the ST onset, which previously was a consonant cluster, can now become a complex segment, by relaxing the condition on sonority difference from $\left|C_{1}-C_{2}\right| \geq 2$ to $\left|C_{1}-C_{2}\right| \geq 1$, so that it undergoes dissimilation of complex segments and drops the more sonorant $\mathrm{S}$. This is what happens in Sanskrit.

Second, the dissimilation rule that occurs preferentially between two TR clusters in Gothic generalizes so that it also occurs between two ST clusters with bond strength 1. This generalization allows ST onsets to dissimilate, the clusters that were previously not allowed to dissimilate because they did not meet the condition that they should be complex segments (cf. Gothic reduplication). A consequence of this extension is that the dissimilation rule can no longer drop the more sonorant $S$ of the ST, for in a consonant cluster with bond strength 1, the internal structure of the cluster is such that neither of the two consonants is secondary: the two consonants are in mere concatenation with each other. In such a case, the dissimilation rule drops the less sonorant $\mathrm{T}$, because it is not only dissimilation but also cluster simplification that participate in the elision process. ${ }^{16)}$ This is what happens in Old Irish.

Note that the foregoing discussion answers the two reflexology questions in (7.2) and (7.3). The onset reduplication in Sanskrit drops R of TR but S of ST because they both are the more sonorant member of the consonant group, which is what typically drops by dissimilation, even though such reduction is against the simple

16) How dissimilation and cluster simplification cooperate in a case like this is beyond this paper. Readers are referred to my earlier works on the topic, e.g. Kim (2019). 
rule of across-the-board $\mathrm{C}_{1^{-}}$or $\mathrm{C}_{2}$ - copying. The ST cluster, on the other hand, varies its elision between Sanskrit and Old Irish, dropping the more sonorant $\mathrm{S}$ in Sanskrit but the less sonorant $\mathrm{T}$ in Old Irish because it functions as a complex segment in the former but as a consonant cluster in the latter, and because dissimilation drops the more sonorant member of a complex segment, but the less sonorant member of a consonant cluster.

Finally, as a summary, I present the following diagram to show how reduplication has interacted with the preferential and generalized rules of dissimilation to yield the diverse shape of the reduplicant in IE languages.

(14) The transfer of TR- vs. ST-onsets by reduplication in IE languages

a. TRV-TRVX > idem, STV-STVX > idem (Hittite)

b. TRV-TRVX $>$ TV-TRVX, STV-STVX $>$ idem (Gothic)

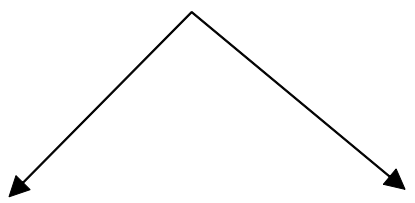
c. TRV-TRVX $>$ TV-TRVX, STV-STVX > SV-STVX
d. TRV-TRVX $>$ TV-TRVX, (Old Irish, Pre-AG) STV-STVX > TV-STVX (Sanskrit)

(14a) in which both TR- and ST-onsets remain in the reduplicant is the incipient state at which all languages in the diagram must have been immediately after reduplication, and Hittite is still at this state. (14b) is the state in which dissimilation has reduced the TR-onset in preference to ST-onset in the reduplicant, at which Gothic is. (14c) and (14d) are the states at which the preferential dissimilation applying only to TR-onset in (14b) has generalized to include the ST cluster. The two are distinguished by how the generalization has occurred. In (14c), the canonical dissimilation rule that occurs typically between complex segments has extended to include the less bound ST cluster. As a result, dissimilation drops the more sonorant $\mathrm{R}$ of TR but the less sonorant T of ST. This is because TR has already undergone the preferential dissimilation and lost the more sonorant member, while ST is newly included in the rule's domain when the restriction on the canonical dissimilation is relaxed. In (14d), on the other hand, the sonority difference condition on forming 
complex segment is relaxed from $\left|\mathrm{C}_{1}-\mathrm{C}_{2}\right| \geq 2$ to $\left|\mathrm{C}_{1}-\mathrm{C}_{2}\right| \geq 1$ so that the ST, a cluster that rarely acts as a complex segment, may also participate in the dissimilation process. This is why unlike in Old Irish (and pre-Ancient Greek) both reflexes of TR and ST in Sanskrit strictly follow the principle that the more sonorant member of the complex segment drops by dissimilation regardless of whether that segment occurs as $C_{1}$ or $C_{2}$ in its internal structure.

\section{Conclusion}

The analysis presented in the preceding sections coherently explains the typology of onset cluster reduplication in Indo-European languages. The following simple notions have made this possible: 1) Reduplication copies the onset in toto; 2) The canonical form of Grassmann's Law type of dissimilation typically occurs between two complex segments, or between segments with bond strength 2;3) Under the principle of preferential rule application, dissimilation occurs to TRVTR in preference to STVST, and to STVST only as a generalization of this preferential dissimilation because TR with its greater intra-cluster sonority difference is more likely to form a complex segment than ST; 4) Problems concerning a rule's condition are separate from those concerning its reflexes: Why TR but not ST reduces by dissimilation in Gothic is a question on the rule's condition, whereas why TR drops $\mathrm{R}$ but $\mathrm{ST}$ varies its elision between $\mathrm{S}$ and $\mathrm{T}$ by dissimilation is a question on the rule's reflex. Probing the preferential condition on the rule reveals four logically possible types in (13), of which only three are predicted to be linguistically possible. Seeking explanation of the rule's variant reflexes, especially the question of why TR always drops $\mathrm{R}$ but ST drops sometimes $\mathrm{S}$ but sometimes $\mathrm{T}$, leads to the revelation that TR always acts as a complex segment in dissimilation of consonant clusters in Indo-European, but ST sometimes acts as a complex segment but sometimes as a consonant cluster. As a result, the more sonorant S drops when ST is a complex segment, but the less sonorant (thus weaker) $\mathrm{T}$ drops when it is a cluster. This analysis under language universals and typology approach thus provides a fine-grained picture of variation in reduplication of root-initial consonant clusters in Indo-European languages, revealing us rare insights into the unity in diversity of language. 


\section{References}

Beekes, R. S. P. (2011). Comparative Indo-European Linguistics ( $2^{\text {nd }}$ ed. revised and corrected by M. de Vaan). Amsterdam/Philadelphia: John Benjamins B.V.

Broselow, E. (2015). The typology of position-quality interactions in loanword vowel insertion. Y. E. Hsiao \& Lian-Hee Wee (Eds.) Capturing Phonological Shades Within and Across Languages (pp. 292-319). Newcastle upon Tyne, UK: Cambridge Scholars Publishing.

Buck, C. D. (1933). Comparative Grammar of Greek and Latin Chicago: The University of Chicago Press.

Cairns, C. E. \& Feinstein, M. H. (1982). Markedness and the theory of syllable structure. Linguistic Inquiry, 13(2), 193-225.

Clements, G. N. (1990). The role of sonority cycle in core syllabification. In John Kingston \& Mary E. Beckman (Eds.) Papers in Laboratory Phonology I: Between the Grammar and Physics of Speech (pp. 283-333). Cambridge, UK: Cambridge University Press.

Dempsey, T. R. (2015). Verbal Reduplication in Anatolian (Doctoral dissertation). University of California, Los Angeles.

Fleischhacker, Heidi A. (2005). Similarity in Phonology: Evidence from Reduplication and Loan Adaptation (Doctoral dissertation). University of California, Los Angeles.

Foley, J. (1974). An extension of Grassmann's Law. In Bauer, Hartig, Krenn, Mayer, Muller and Pott (Eds.) Studien zur Generativen Transformationsgrammatik. Atheneum Verlag.

Foley, J. (1977). Foundations of Theoretical Phonology. Cambridge: Cambridge University Press.

Foley, J. (1981). Philosophy of Linguistics. Ms. Dept. of Linguistics, Simon Fraser University, Vancouver.

Foley, J. (1985). Quatre principes de l'analyse morphologique Langages, 78, 57-72. Paris: Librairie Larousse.

Garrett, A. \& Johnson, K. (2011). Phonetic bias in sound change. UC Berkeley Phonology Lab Annual Report, Berkeley, CA: Dept. of Linguistics, University of California.

Gnanadesikan, A. E. (2009). The Writing Revolution: Cneiform to the Internet. Malden, MA: Wiley-Blackwell.

Greenberg, J. (1978). Some generalisations concerning initial and final consonant clusters. In J. Greenberg (Ed.) Universals of Human Languages Vol. 2: Phonology (pp. 243-279). Stanford: Stanford University Press.

Kim, H. -S. (1991). Universal Phonological Processes: a theoretical analysis of dissimilation, cluster simplification, and their synergy for consonant cluster reduction in Romance and IndoEuropean languages (Doctoral dissertation). Simon Fraser University, Vancouver.

Kim, H. -S. (1999). Meinhof's rule in Bantu revisited; with special reference to Chibemba. Linguistics, 7(2), 183-205. The Linguistic Association of Korea.

Kim, H. -S. (2019). Wrong side reduplications in Salish and Temiar: synergy of dissimilation and cluster simplification. Studies in Phonetics, Phonology and Morphology, 25(3), 439-463. The Phonology-Morphology Circle of Korea. 
Kiparsky, P. (1979). Metrical structure assignment is cyclic. Linguistic Inquiry, 10(3), 421-441.

Kiparsky, P. (1981). Remarks on the metrical structure of the syllable. In W. Dressler, O. Pfeiffer \& J. Rennison (Eds.) Phonologica 1980 (pp. 245-256). Innsbruck: Innsbrucker Beiträge zur Sprachwissenschaft.

Kloekhorst (2008). Etymological Dictionary of the Hittite Inherited Lexicon. Leiden/Boston: Brill. McCarthy, J. J. \& Prince, A. (1995). Faithfulness and reduplicative identity. Papers in Optimality Theory, 10. Retrieved from https://scholarworks.umass.edu/linguist_faculty_pubs/10.

Meinhof, C. (1932). Introduction to the Phonology of the Bantu Languages, Trans. by N. J. van Warmelo. Berlin: Dietrich Reimer/Ernst Vohsen.

Niedermann, M. (1953). Précis de Phonétique Historique du Latin, Paris: Librairie C. Klincksieck. Ohala, John J. (1981). The listener as a source of sound change. In Carrie S. Masek, Roberta A. Hendrick and Mary Frances Miller (Eds.) Papers from the Parasession on Language Behavior (pp. 178-203). Chicago: Chicago Linguistic Society.

Scheer, Tobias \& Segeral, P. (2005). What lenition and fortition tell us about Gallo-Romance muta-cum-liquida. In T. Geerts, I. V. Ginneken and H. Jakobs (Eds.) Romance Languages and Linguistic Theory 2003: Selected Papers from 'Going Romance' 2003, Niejmegen, 20-22 November (pp. 235-268). Amsterdam/Philadelphia: John Benjamins Publishing Company.

Sihler, A. L. (1995). New Comparative Grammar of Greek and Latin, New York \& Oxford: Oxford University Press.

Smyth, H. W. (1966). Greek Grammar. Cambridge: Harvard University Press.

Song, Jaemog (2018). Halha Monggoleuy Meyari Jungchup (Echo reduplication in Khalkha Mongolian). Monggolhak, 52, 145-169. The Korean Association for Mongolian Studies.

Steriade, D. (1988). Reduplication and syllable transfer in Sanskrit and elsewhere. Phonology, $5,73-155$.

Thurneyson, R. (1946). A Grammar of Old Irish. Dublin: Dublin Institute for Advanced Studies. Weiss, M. (2009). Outline of the Historical and Comparative Grammar of Latin. Ann Arbor and New York: Beech Stave Press.

Whitney, W. D. (1889). Sanskrit Grammar. Cambridge: Harvard University Press.

Wright, J. (1954). A Grammar of the Gothic Language. Oxford: Clarendon Press.

Yates, A. D. \& Zukoff, S. (2018). The phonology of Anatolian reduplication: synchrony and diachrony. Indo-European Linguistics, 6, 201-270. Leiden/Boston: Brill.

Zukoff, S. (2017). Indo-European reduplication: synchrony, diachrony, and theory (Doctoral dissertation). University of California, Los Angeles. 
Hyung-Soo Kim

Researcher

Language Research Institute

Hankuk University of Foreign Studies

107 Imunro, Dongdaemoon-gu, Seoul 02450, Korea

E-mail: csjennykim@hanmail.net

Professor (Emeritus)

Dept. of English Education

Jeonju University

303 Cheonjamro, Wansan-gu, Jeonju, Jeonbuk 55069, Korea

E-mail: csjennykim@jj.ac.kr

Received: October 31, 2019

Revised version received: January 6, 2020

Accepted: January 29, 2020 